(C) 2022, The Authors. Published by Elsevier Inc. and Fass Inc. on behalf of the American Dairy Science Association ${ }^{\circledR}$. This is an open access article under the CC BY license (http://creativecommons.org/licenses/by/4.0/).

\title{
Chemiluminescence sensors based on molecularly imprinted polymers for the determination of organophosphorus in milk
}

\author{
Yinchuan Pan, ${ }^{1} \odot$ Xu Liu, ${ }^{1} \odot$ Jing Liu, ${ }^{1} \odot$ Jianping Wang, ${ }^{1} \odot$ Juxiang Liu, ${ }^{1} \odot$ Yanxia Gao, ${ }^{2,3,4 *} \odot$ and $\mathrm{Ning} \mathrm{Ma}^{1 *} \odot$ \\ ${ }^{1}$ College of Veterinary Medicine, Hebei Agricultural University, Baoding, Hebei 071001, P.R. China \\ ${ }^{2}$ College of Animal Science, Hebei Agricultural University, Baoding, Hebei 071001, P.R. China \\ ${ }^{3}$ Hebei Technology Innovation Center of Cattle and Sheep Embryo, Baoding, Hebei 071001, P.R. China \\ ${ }^{4}$ Hebei Research Institute of Dairy Industry Technology, Shijiazhuang, Hebei 050221, P.R. China
}

\section{ABSTRACT}

As a food adapted to all kinds of people, milk has a high nutritional value. Because milk is a complex biological matrix, detecting illegal compounds is often difficult. As a common pesticide, organophosphorus (OP) residues caused by nonstandard use may be ignored, which is a threat to milk quality. In this study, using coumaphos as template molecule, the synthesized molecularly imprinted polymer (MIP) can specifically recognize 7 kinds of OP. Then, the MIP was used as an identification element to prepare a chemiluminescence sensor on a 96-well microplate for the determination of $\mathrm{OP}$ residues in milk samples. Due to the 4-(imidazol1-yl)phenol-enhanced luminol- $\mathrm{H}_{2} \mathrm{O}_{2}$ system, the sensitivity of the system is very high; the detection limits of 7 OP including coumaphos, fenthion, chlorpyrifos, parathion, diazinon, fenchlorphos, and fenitrothion were 1 to $3 \mathrm{pg} / \mathrm{mL}$, and the half maximal inhibitory concentrations were 1 to $20 \mathrm{ng} / \mathrm{mL}$. The intraday recoveries of 7 OP were in the range of 86.1 to $86.5 \%$, and the interday recoveries were in the range of 83.6 to $94.2 \%$. Furthermore, the sensor can be reused up to 5 times. Therefore, the MIP-based chemiluminescence sensor can be used as a routine tool to detect OP residues in milk samples.

Key words: organophosphorus, computational simulation, molecularly imprinted polymer, chemiluminescence sensor

\section{INTRODUCTION}

Organophosphorus (OP) is a category of organic compounds containing phosphorus and used to control plant diseases and insects, which have strong insecti-

\footnotetext{
Received August 27, 2021.

Accepted November 23, 2021

*Corresponding authors:
} maning9618@163.com cidal and bactericidal abilities. Due to the advantages of low cost, high efficacy, and short half-life, OP are widely used in agriculture. However, with the huge consumption of OP, more and more OP remain in food and the environment, which has become a great threat to the ecological environment and human health (Marques et al., 2018). According to the Environmental Protection Agency, OP are classified as highly toxic or moderately toxic, and the main harm of OP to the human body is neurological damage (Wei et al., 2018). The toxicological mechanism of OP is the inhibition of cholinesterase activity, which leads to the accumulation of acetylcholine, causing sweating, tremors, severe respiratory paralysis, and even death (Eddleston, 2019).

It has been reported that OP hydrolyze slowly in milk and cause risks to human health (Lin et al., 2020). Milk contains fat and protein, which is a complex biological matrix (Rodrigues et al., 2011). Residues of OP in milk can be produced by direct application of OP pesticide to control parasites, indirect ingestion of OP pesticide through contaminated feed, and exposure to a contaminated environment (Gazzotti et al., 2009). Many countries, including China and the EU, have determined maximum residue limits of $\mathrm{OP}$ in foods (Xin et al., 2012). The EU has ruled that the residual of OP such as quinalphos, triazophos, parathion, and fenthion cannot be detected in milk, and China sets a maximum limit of $0.5 \mu \mathrm{g} / \mathrm{L}$ in drinking water and 0.1 $\mu \mathrm{g} / \mathrm{L}$ for a single sample (Huang et al., 2019), while the EU sets residue limits for vegetable oils and fats to 10 $\mu \mathrm{g} / \mathrm{kg}$ (Boulanouar et al., 2017). Detection methods for OP mainly include HPLC, ELISA, and GC (Xu et al., 2011; Zhao et al., 2014; Harshit et al., 2017). In addition, some researchers have also developed novel methods to detect OP in milk samples. For example, using magnetic covalent organic framework as adsorbent, a simple and efficient magnetic solid-phase extraction method was established to detect OP in fatty milk (Lin et al., 2020). As extraction material, a metal-organic framework combined with $\mathrm{Fe}_{3} \mathrm{O}_{4}$ has been applied for 
simultaneous determination of 5 OP in vegetables, fruit juice, and milk by GC analysis (Ghorbani et al., 2021).

Among the analytical methods, ELISA can detect multiple samples simultaneously and is used as a rapid screening method. However, conventional ELISA has many disadvantages. First, ELISA detection requires the participation of antibodies, but it is tedious to produce them. Second, the antibodies can be used only once. Third, a single assay takes several hours. Therefore, a need exists to detect $\mathrm{OP}$ residues by a wide range of detection methods with high efficiency and high sensitivity. However, the traditional ELISA method still uses conventional antibodies as the recognition element and cannot be reused.

Molecularly imprinted polymers (MIP), known as plastic antibodies, have been used to synthesize molecular recognition materials with specific adsorption to specific target molecules ( $\mathrm{Li}$ et al., 2019a). Moreover, MIP synthesis is convenient and efficient, and the synthesized MIP can be reused many times. The MIP technique is widely used in various fields, such as residue detection, chromatographic separation, solid-phase extraction, simulated enzyme catalysis, biomedicine, and biomimetic sensing (Chen et al., 2018). Chemiluminescence $(\mathbf{C L})$ is a kind of molecular luminescence spectral analysis method (Sun et al., 2021). With the advantages of high sensitivity, fast detection speed, simple operation, and low cost, CL is widely used in clinical diagnosis, environmental monitoring, drug residue detection, and other fields (Zhang et al., 2018). For example, some researchers synthesized a metal-organic framework to catalyze a luminol- $\mathrm{H}_{2} \mathrm{O}_{2}$ CL reaction, and used it to detect glucose in human serum and urine with detection limit of $10^{-8} \mathrm{~mol} / \mathrm{L}$ (Li et al., 2019b). Therefore, an MIP-based CL detection system inherits the advantages of ELISA and CL methods, and may be used as a new method to detect OP (Figure 1).

At present, researchers have used CL and MIP in combination to detect illegal compounds such as chloramphenicol, Sudan dyes, phenothiazines, and benzodiazepines in meat and eggs (Xia et al., 2018; He et al., 2019; Jia et al., 2019). The MIP-based CL detection system may be used as a new method to detect OP. However, to our best knowledge, the combination of MIP and CL has not yet been applied for OP detection in milk samples. In this study, MIP of OP was synthesized and coated on a 96-well microplate. A luminol$\mathrm{H}_{2} \mathrm{O}_{2}$ system was used to stimulate the luminescence signal to detect OP. With the advantages of simplicity, good selectivity, super sensitivity, and recyclability, the MIP-based microtitration CL (MIP-MCL) sensor prepared in this study combines the advantages of MIP, ELISA, and CL, and is suitable for screening large quantities of milk samples.

\section{MATERIALS AND METHODS}

\section{Reagents and Chemicals}

Coumaphos, fenthion, chlorpyrifos, parathion, diazinon, fenchlorphos, fenitrothion, isocarbophos (ICP), ribavirin, amantadine, sulfamethoxydiazine, and oxytetracycline were purchased from the Chemical Metrology and Analytical Science Division of the National Institute of Metrology (Beijing, China), and 4-(imidazol-1-yl)phenol (IMP) and horseradish peroxidase (HRP) were purchased from Sigma-Aldrich. Ethylene glycol dimethacrylate was purchased from Aladdin Industrial Corporation. Methacrylic acid (MAA), 2,2-azobis(isobutyronitrile), and polyvinyl alcohol were purchased from Tianjin Kemiou Chemical Reagent Co. Ltd. Luminol was purchased from Acros. An opaque 96-well microtiter plate was purchased from Jingan Biotechnology Co. Ltd. Other chemical reagents were purchased from Beijing Chemical Company, and all of them were of analytical grade or better.

The standard solutions of $7 \mathrm{OP}$ were dissolved in methanol, and their working solutions $(1 \mathrm{pg} / \mathrm{mL}$ to 1 $\mathrm{mg} / \mathrm{mL}$ ) were diluted with water. We prepared PBS ( $\mathrm{pH} 7.2$ ) by dissolving $0.2 \mathrm{~g}$ of $\mathrm{KH}_{2} \mathrm{PO}_{4}, 0.2 \mathrm{~g}$ of $\mathrm{KCl}$, $1.15 \mathrm{~g}$ of $\mathrm{Na}_{2} \mathrm{HPO}_{4}$, and $8.0 \mathrm{~g}$ of $\mathrm{NaCl}$ in $1,000 \mathrm{~mL}$ of water. The CL reagents (luminol, $\mathrm{H}_{2} \mathrm{O}_{2}$, and IMP) were prepared with Tris- $\mathrm{HCl}(0.1 \mathrm{~mol} / \mathrm{L}, \mathrm{pH} 8.6)$, respectively.

\section{Computation Simulation}

Chem3D (version 18.0.0.231, CambridgeSoft) was used to analyze the structures of $7 \mathrm{OP}$. The 3-dimensional structures of $7 \mathrm{OP}$ were displayed by Chem3D. In this study, the calculated results of 7 OP were used to explain the difference in MIP identification. As shown in Figure 2, the core structure of the $7 \mathrm{OP}$ is thiophosphate ester, which is almost the same in the 3-dimensional conformations of the molecules. Their tetrahedral structures are centered on phosphorus atoms, bond angles between $102^{\circ}$ and $115^{\circ}$ (Table 1 ), and the side chains are connected to oxygen atoms in the core structure. Compared with the other 6 OP, the side chain of coumaphos has two 6-membered rings, which have large steric hindrance. The other 6 OP could enter the 3-dimensional pores imprinted with coumaphos, and it was reasonably speculated that MIP synthesized with the template molecule of coumaphos can simultaneously identify 7 types of OP with high adsorption rates. Therefore, coumaphos was used as a template molecule in the present study.

Molecularly imprinted polymers adsorb molecules through pores on the surface. An MIP synthesized with 


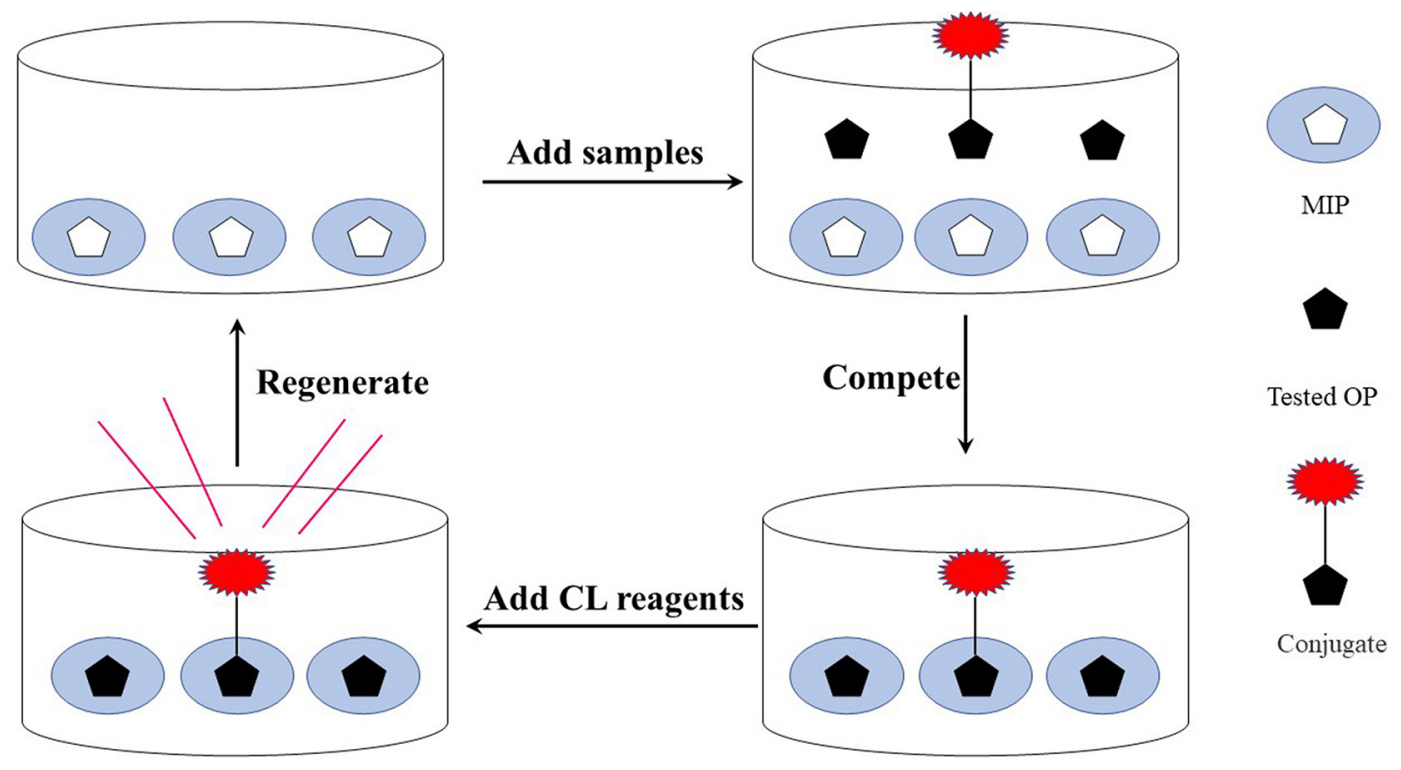

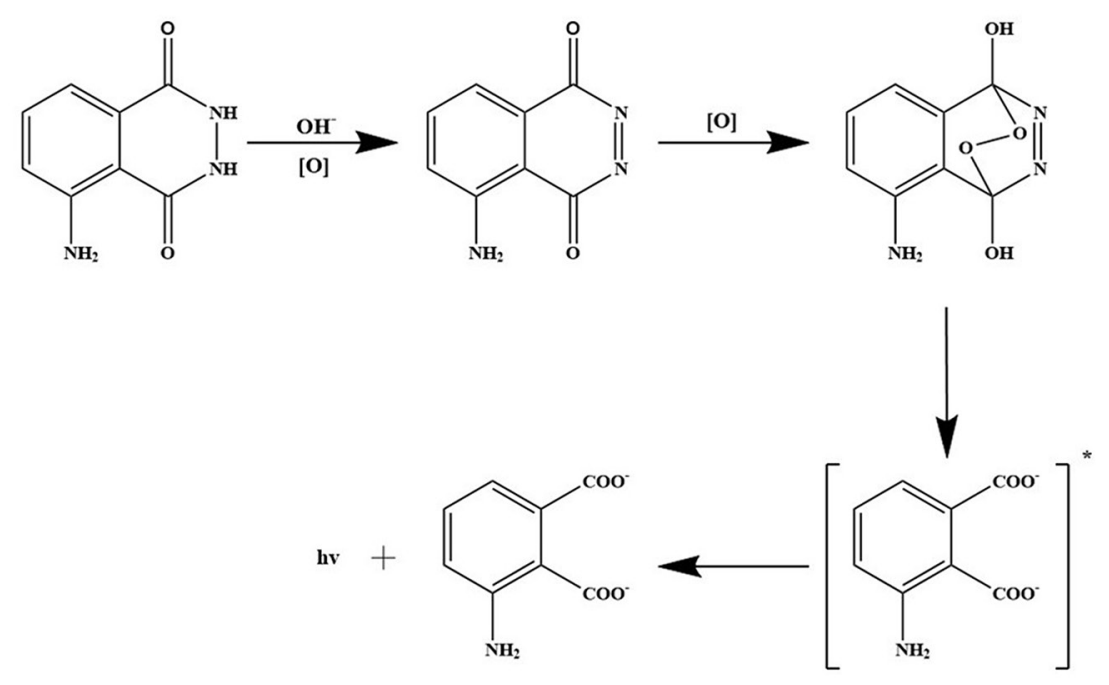

\section{CL principle}

Figure 1. Principle of molecularly imprinted polymer (MIP)-based microtitration chemiluminescence (CL) sensors in organophosphorus (OP) detection.

coumaphos, with large steric hindrance, as a template molecule should have a good adsorption effect. As shown in Figure 2, the side chain of coumaphos is relatively large, so it is speculated that the MIP synthesized with coumaphos as the template molecule can specifically adsorb 7 OP.

\section{Synthesis of MIP}

In this study, MIP were synthesized by the bulk polymerization method (He et al., 2021). During the experiments, MIP of 3 proportions were synthesized by changing the ratio of the template molecule and the functional monomer MAA. (1:4, 1:6, 1:8). The synthesis process was shown as follows: briefly, $0.1 \mathrm{mmol}$ of coumaphos and $0.6 \mathrm{mmol}$ of MAA were added into a flask containing $7 \mathrm{~mL}$ of chloroform. After fully mixing, the ultrasound was oscillated for $15 \mathrm{~min}$, sealed, and stored at $4^{\circ} \mathrm{C}$ for $12 \mathrm{~h}$. Then, $3 \mathrm{mmol}$ of ethylene glycol dimethacrylate and $0.04 \mathrm{~g}$ of 2,2-azobis(isobutyronitrile) were added. After mixing, nitrogen was blown for $5 \mathrm{~min}$, and the mixture was immediately sealed and stirred for $24 \mathrm{~h}$ 


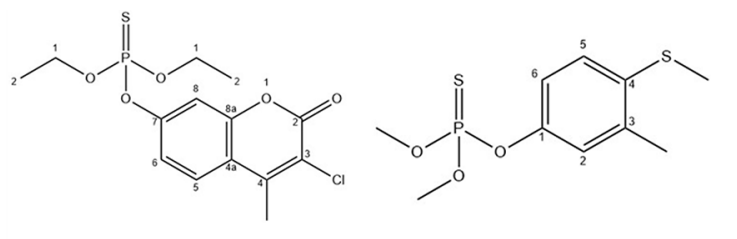<smiles>CCOC(=O)Cc1c(Cl)cc(Cl)c(Cl)c1OCC</smiles>

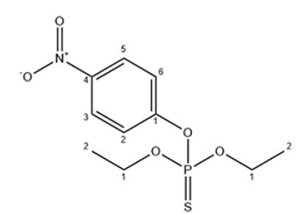

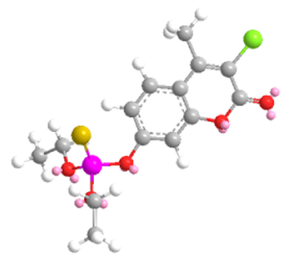

Coumaphos<smiles>CCOP(=S)(OCC)Oc1cc(C)nc(C(C)C)n1</smiles>

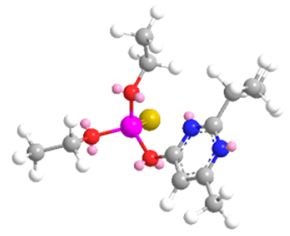

Diazinon

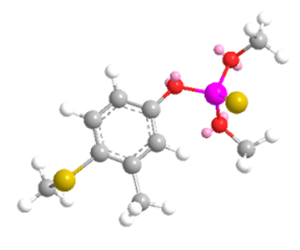

Fenthion
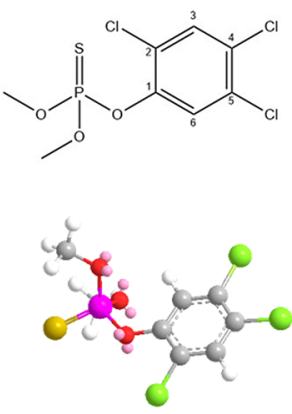

Fenchlorphos

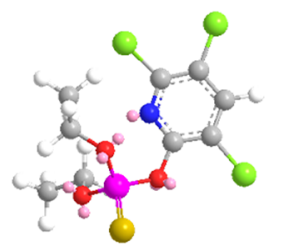

Chlorpyrifos<smiles>C=C(OC)Oc1ccc(C(=O)OC)c(C)c1</smiles>

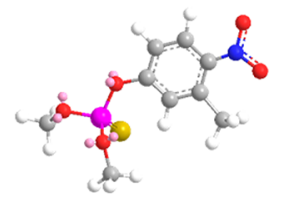

Fenitrothion

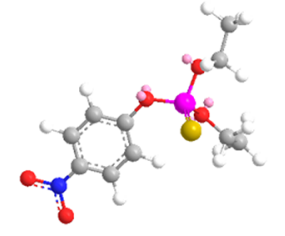

Parathion

Figure 2. Two- and three-dimensional structures of 7 organophosphorus.

in a water bath $\left(60^{\circ} \mathrm{C}\right)$ to complete the polymerization reaction. The resulting sample was ground to particles of 32 to $75 \mu \mathrm{m}$ in size. The collected fine particles were put into a Soxhlet device and extracted continuously with methanol and acetic acid (95/5, vol/vol) for $48 \mathrm{~h}$. After that, methanol was replaced, and then Soxhlet extraction was performed for $24 \mathrm{~h}$ to remove the templates. Finally, MIP particles were dried at $70^{\circ} \mathrm{C}$ to constant weight for subsequent use. The nonimprinted polymer (NIP) was synthesized by the same method but without the template.

\section{Preparation of HRP-Labeled Conjugates}

The competitive conjugate was prepared by coupling ICP to HRP by use of a glutaraldehyde method. Briefly, $7 \mathrm{mg}$ of ICP was dissolved in as little dimethylformamide as possible, and the solution was cooled to $4^{\circ} \mathrm{C}$ (solution A). A total of $16 \mathrm{mg}$ of HRP was dissolved in $6 \mathrm{~mL}$ of PBS (solution B). Solution A was slowly added to solution $\mathrm{B}$, and $3.3 \mu \mathrm{L}$ of glutaraldehyde was added. The resulting mixture was gently stirred at $4^{\circ} \mathrm{C}$ for $6 \mathrm{~h}$. The solution was then dialyzed in PBS for $3 \mathrm{~d}$ to obtain

Table 1. Bond angles $\left(^{\circ}\right)$ of 7 organophosphorus parent structures

\begin{tabular}{|c|c|c|c|c|c|c|}
\hline Item & S-P-O(1) & S-P-O(2) & S-P-O(3) & $\mathrm{O}(1)-\mathrm{P}-\mathrm{O}(2)$ & $\mathrm{O}(1)-\mathrm{P}-\mathrm{O}(2)$ & $\mathrm{O}(2)-\mathrm{P}-\mathrm{O}(3)$ \\
\hline Coumaphos & 115.649 & 112.263 & 110.730 & 102.623 & 102.998 & 103.498 \\
\hline Fenthion & 113.467 & 114.309 & 109.545 & 104.731 & 105.407 & 108.889 \\
\hline Chlorpyrifos & 107.731 & 107.259 & 107.358 & 112.186 & 110.960 & 111.105 \\
\hline Parathion & 113.370 & 114.620 & 109.272 & 104.901 & 105.622 & 108.561 \\
\hline Diazinon & 106.061 & 107.880 & 108.148 & 113.959 & 111.733 & 108.811 \\
\hline Fenchlorphos & 112.729 & 112.997 & 105.694 & 108.537 & 108.346 & 108.322 \\
\hline Fenitrothion & 112.588 & 114.759 & 109.582 & 105.584 & 105.364 & 108.451 \\
\hline
\end{tabular}



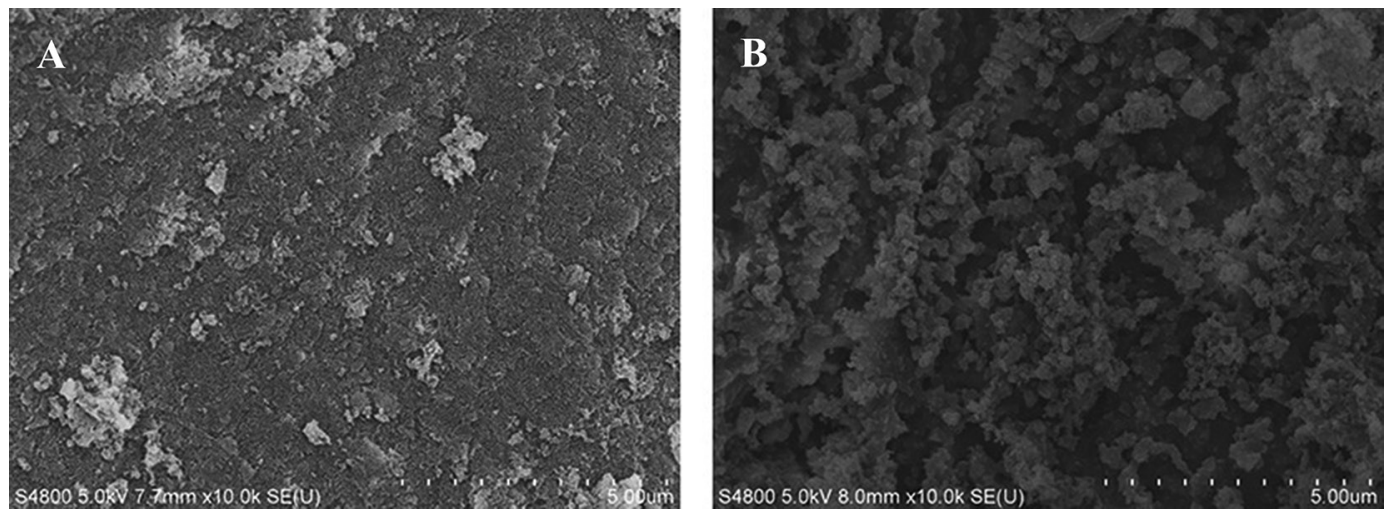

Figure 3. Scanning electron microscopy of the nonimprinted polymers (A) and molecularly imprinted polymers (B).

HRP-ICP. The resulting conjugate was characterized by UV scanning.

\section{Preparation of the MIP-MCL Sensor}

In this study, the sensors were tested in a competitive manner. The specific experimental steps are as follows. The $5 \mathrm{mg}$ of MIP was suspended in $1 \%$ polyvinyl alcohol, and the mixture was sonicated for $15 \mathrm{~min}$. The resulting suspension was added to a 96-well microplate
(50 $\mu \mathrm{L}$ per well). The plate was incubated at $50^{\circ} \mathrm{C}$ for 3 h. Then $50 \mu \mathrm{L}$ of solution (sample extract) and $50 \mu \mathrm{L}$ of diluted HRP-ICP was added to the well and incubated at room temperature for $30 \mathrm{~min}$. The wells were washed with water 3 times $(200 \mu \mathrm{L}$ per well). Then IMP, luminol, and $\mathrm{H}_{2} \mathrm{O}_{2}$ were added into the wells $(50 \mu \mathrm{L}$ per well for each compound). After incubating at room temperature for $120 \mathrm{~s}$, CL intensities were measured in a Synergy HTX Multimode Reader (BioTek Instruments Inc.). Finally, the wells were washed with a methanol

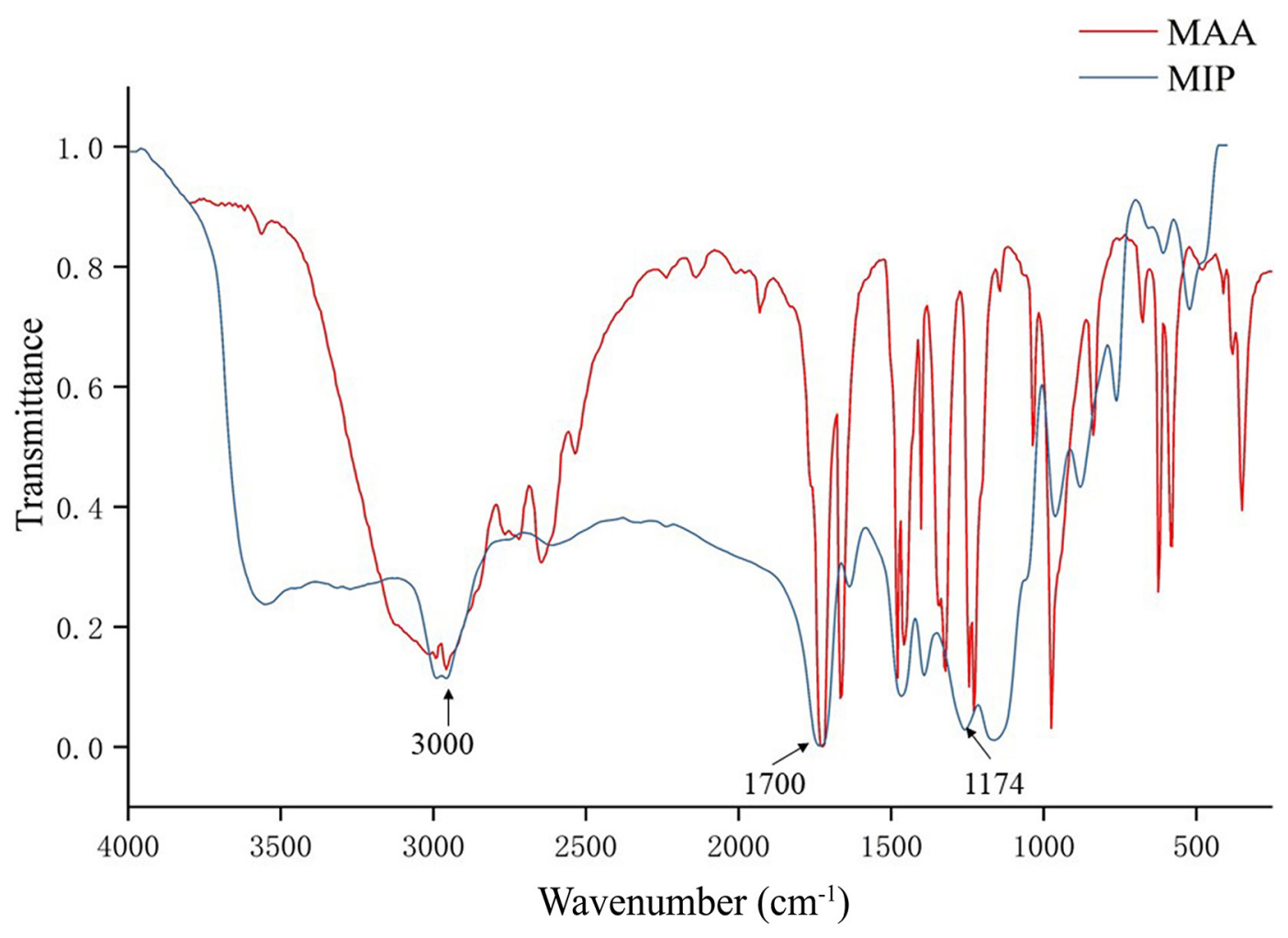

Figure 4. Fourier-transform infrared spectroscopy scan spectrum of molecularly imprinted polymers (MIP) and methacrylic acid, the functional monomer of MIP (MAA). 
and acetic acid mixture $(95 / 5, \mathrm{vol} / \mathrm{vol})$ to remove absorbed analytes for the next use. The competitive inhibition curve of OP was drawn by the relationship between OP concentration and inhibition rate $\left(\mathrm{B} / \mathrm{B}_{0}\right.$, CL intensity of standard divided by that of the blank standard). The half maximal inhibition concentration $\left(\mathbf{I C}_{50}\right)$ and the limit of detection (LOD) were defined as $50 \%$ and $10 \%$ inhibition curves corresponding to OP concentrations, respectively.

\section{Sample Preparation}

We randomly purchased samples of milk from several local supermarkets. These milk samples were analyzed with the MIP-MCL sensor. The sample processing method was carried out according to a previous report (Ghorbani et al., 2021; He et al., 2021). Briefly, $0.1 \mathrm{~g}$ of $\mathrm{CH}_{3} \mathrm{COONa}, 0.3 \mathrm{~g}$ of $\mathrm{MgSO}_{4}$, and $1.5 \mathrm{~mL}$ of acetonitrile were added to $5 \mathrm{~mL}$ of milk to precipitate the protein. The suspension was centrifuged at $3,703 \times g$ for 10 min to obtain the supernatant, and this procedure was repeated 5 times to completely remove the protein in the milk. The supernatant was evaporated to $5.0 \pm 0.5$ $\mathrm{mL}$ at $35^{\circ} \mathrm{C}$ and diluted to $10.0 \mathrm{~mL}$ with water. The equivalent of $1,10,100 \mathrm{ng} / \mathrm{mL}$ of the $\mathrm{OP}$ was added to the resulting liquid. Intraday recovery was calculated when multiple samples were measured on the same day, and interday recovery was calculated when one sample was measured on multiple days.

\section{RESULTS AND DISCUSSIONS}

\section{Characterization of the MIP}

In this study, the synthesized MIP and NIP were scanned by scanning electron microscope. As shown in Figure 3, the surface of MIP was rough with numerous pores, whereas the NIP was smooth, indicating that the template molecule had successfully imprinted on the MIP. In this study, the bulk polymerization method was used to synthesize MIP. This method is easy to operate and does not require other solvents. Moreover, the pores formed by bulk polymerization method are deeper than those formed by other methods such as the surface imprinting method, which is very conducive to the full combination of the $7 \mathrm{OP}$ with similar chemical structure to be tested in this study (He et al., 2021).

The synthesized MIP and functional monomer MAA were scanned by Fourier-transform infrared spectroscopy. The result is shown in Figure 4. It was found that the structure of the 2 substances was basically the same. Both MAA and MIP had $\mathrm{C}=\mathrm{C}$ characteristic peaks at $1,703 \mathrm{~cm}^{-1}$. Additionally, $\mathrm{C}-\mathrm{H}$ characteristic peaks were found in all at 3,250 to $3,000 \mathrm{~cm}^{-1}$, and the $\mathrm{C}-\mathrm{O}$ characteristic peak could be seen at $1,174 \mathrm{~cm}^{-1}$. However, in the MIP spectrum, the waveform of the characteristic peak of $\mathrm{C}=\mathrm{C}$ obviously changed, and the transmittance increased notably. The results showed that MAA existed in the polymer, and strong intermolecular interaction was generated. After the template molecules were eluted, pores matching their functional groups were left. These results showed that the MIP could be used for subsequent testing.
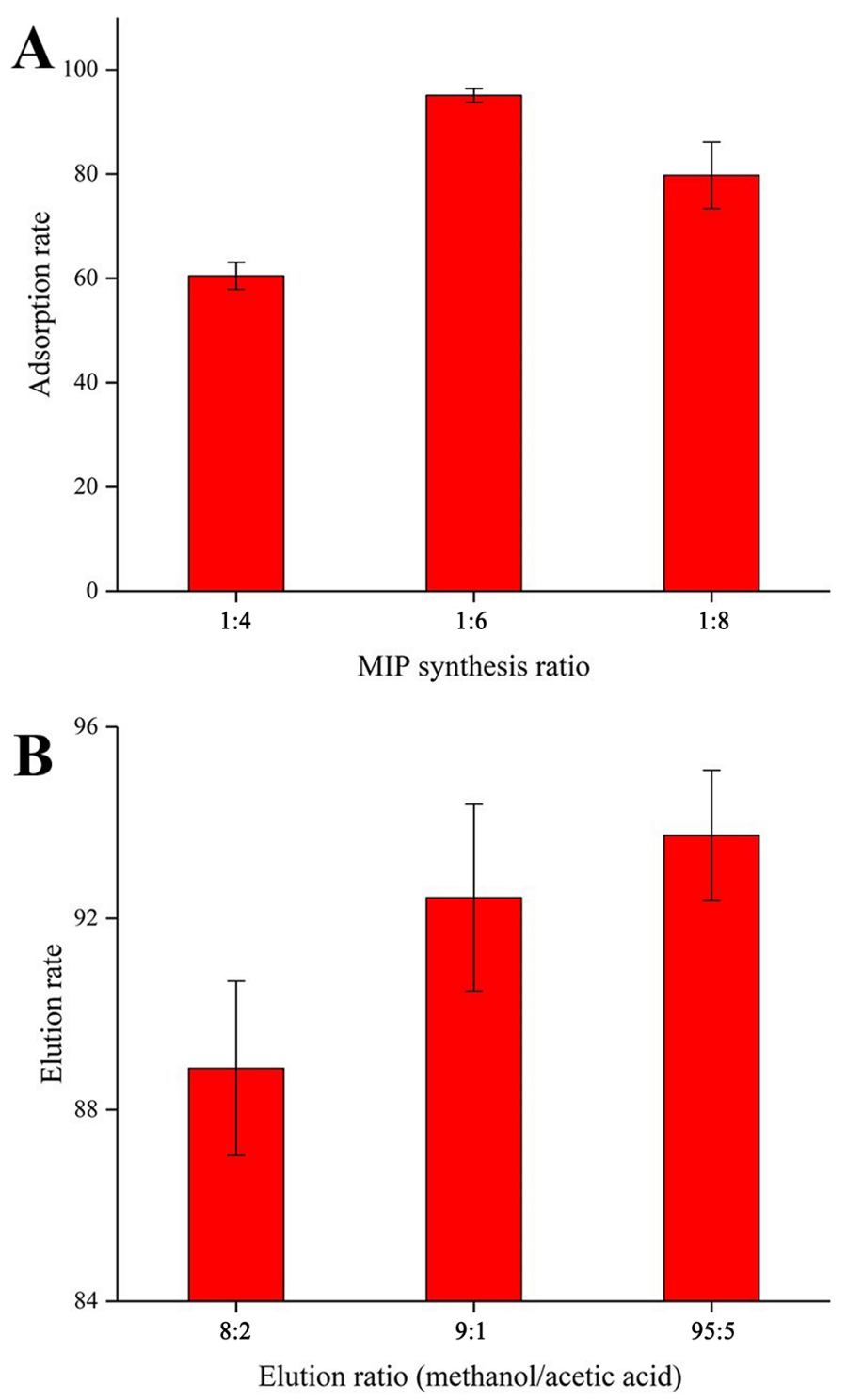

Figure 5. Absorption rate of molecularly imprinted polymers (MIP) synthesized at different ratios (A) and elution rates of different proportions of elution solvent (B). Data are expressed as the mean \pm SD. 


\section{Synthesis Ratio of MIP and Elution Solvent}

According to previous reports, the MIP of OP were synthesized using different template molecules, including dimethylthiophosphoryl, chlorpyrifos, and malathion (He et al., 2015; Wang et al., 2015; Chen et al., 2017; Ma et al., 2018). However, these MIP could only identify a few OP. In this study, 7 OP were specifically identified by MIP synthesized using coumaphos as a template molecule. In this study, MIP was synthesized using 3 ratios of template molecule to functional monomer $(1: 4,1: 6,1: 8)$. The adsorption rates of the 3 synthesized MIP were examined, and the results are shown in Figure 5A. It can be seen that MIP synthesized at the ratio of 1:6 had the maximum adsorption rate, so the ratio of 1:6 was selected for subsequent tests.

Organophosphorus are mainly divided into phosphate ester and phosphorothioate ester categories. In this study, 7 OP with phosphorothioate structure were selected and detected. There is no distinct structure difference between phosphate ester and phosphorothioate ester. In the present study, MIP was synthesized with coumaphos containing phosphorothioate ester, and it was speculated that adsorption effects of MIP also occurred for OP with phosphate ester structure.

Elution solvent plays a very important role in subsequent experiments. The solvent with a high elution rate can elute the MIP-adsorbed OP thoroughly to facilitate the next use of the sensor. Acetic acid can break the chemical bond formed between the OP and MIP. In this study, methanol was used as a solvent for OP. Therefore, methanol-acetic acid was chosen as the elution solvent. Elution solvent with different ratios of methanol to acetic acid (8:2, 9:1, 95:5) was prepared, and their elution ratios were measured in the present study. As shown in Figure 5B, the maximum elution

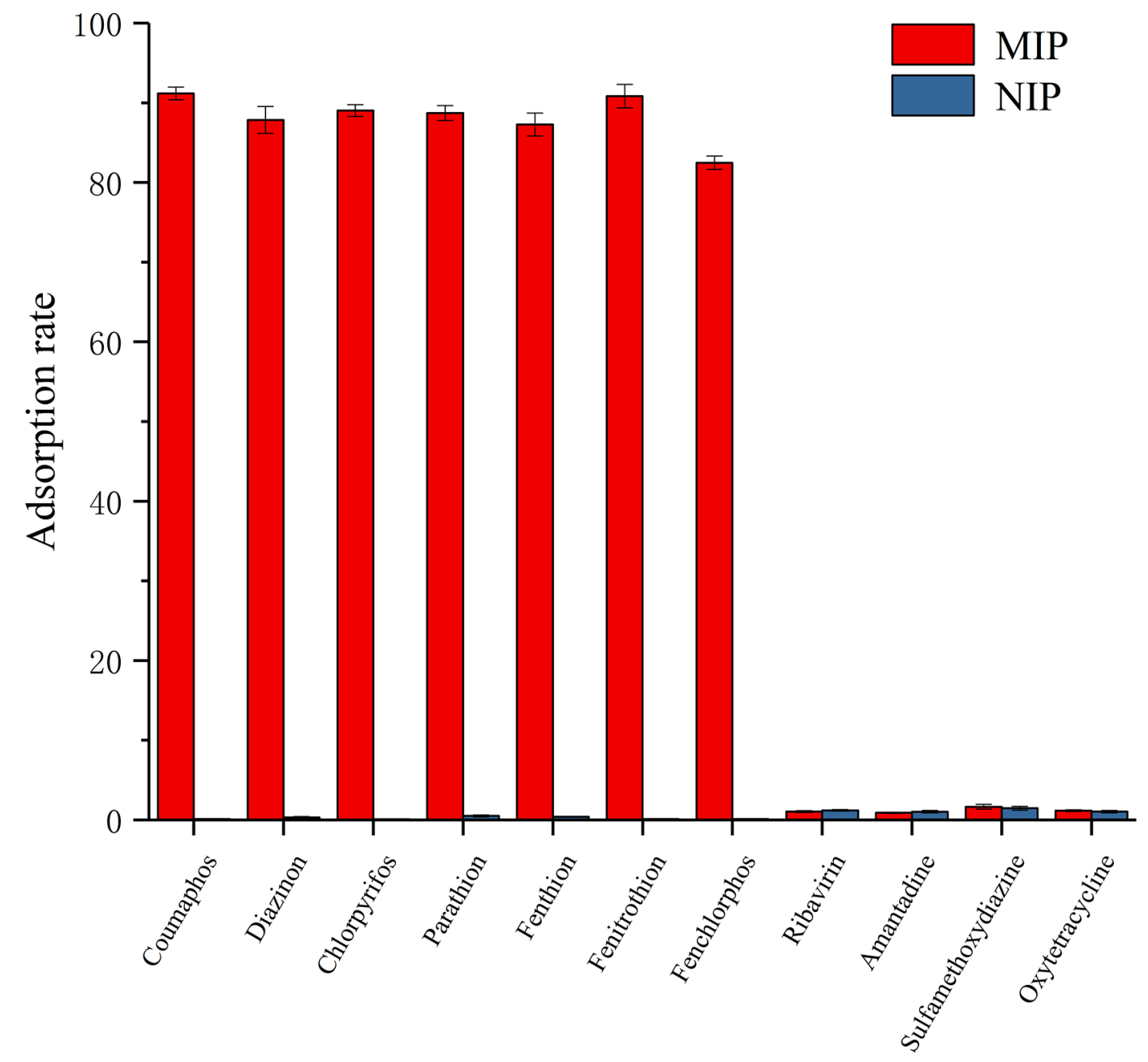

Figure 6. Adsorption rate of molecularly imprinted polymers (MIP) and nonimprinted polymers (NIP) for compounds. Data are expressed as the mean $\pm \mathrm{SD}$. 
rate was obtained with methanol to acetic acid at the ratio of $95: 5$, so this elution solvent was used for subsequent tests.

The adsorption rate of the MIP was measured by UV scanning. The results showed that the adsorption capacity of MIP on OP was obviously higher ( $>80 \%)$ than that of NIP, and the NIP adsorption rate was negligible $(<1 \%)$ compared with the MIP (Figure 6). These results proved that the pores on the MIP surface were beneficial for the absorption of OP.

To verify the specificity of MIP, we measured the adsorption rate of MIP to other compounds, including ribavirin, amantadine, sulfamethoxydiazine, and oxytetracycline. As shown in Figure 6, the MIP showed high adsorption rates $(>80 \%)$ for all tested OP and low adsorption rates $(<1 \%)$ for other compounds, indicating that the MIP could only specifically recognize OP. It is well known that the specific adsorption capacity of MIP is determined by the formation of imprinted pores on the MIP surface, which has been confirmed by previous reports (Tiwari and Prasad, 2015; Kubo and
Otsuka, 2016). In Figure 2, we can see that 7 OP have similar 2-dimensional structures. As shown in Figure 2 and Table 1, the thiophosphate groups of 7 OP have similar bond angles, except that the side chains are different. Therefore, MIP using coumaphos as a template molecule can specifically recognize these $7 \mathrm{OP}$. There are no imprinting pores on the NIP surface, so the adsorption rate of NIP on OP is almost nonexistent. The other 4 compounds we selected have large structural differences compared with OP and could not be adsorbed specifically by the imprinting pores formed on the surface of MIP. Therefore, the adsorption rate of MIP to other compounds was negligible.

\section{Characterization of HRP-ICP}

An enzyme-labeled conjugate was needed for competitive luminescence assays in the pore. In this study, we chose ICP and HRP to prepare the enzyme conjugate. As shown in Figure 7, the synthesized conjugate had the characteristic peaks of HRP and ICP, indicating

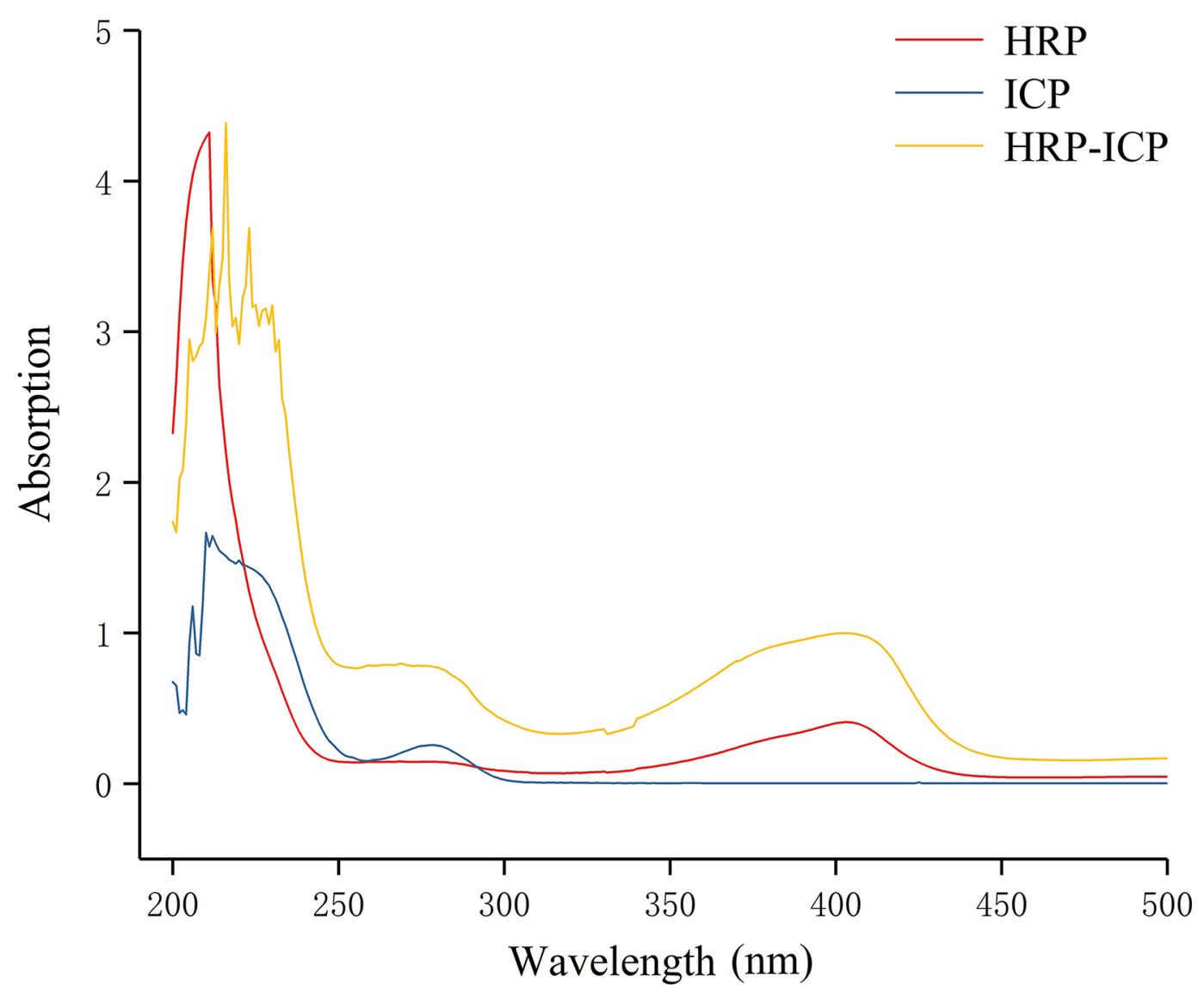

Figure 7. Ultraviolet absorption diagrams of HRP, HRP-ICP, and ICP. HRP = horseradish peroxidase; ICP = isocarbophos. 
that the HRP-ICP conjugate was successfully synthesized and could be used in the following experiments.

\section{Optimization of Assay Parameters}

Conjugate and MIP Concentrations. As a recognition element, the amount of MIP fixed in the well has an important effect on the luminescence system. A small amount of MIP cannot obtain a high luminous signal, and an excessive amount of MIP needs more compounds to occupy the recognition cavity, leading to reduction of sensitivity. The concentration of the conjugates, which are luminescence competitors, also has an important effect on the luminescence system. In this study, coumaphos was used as a substitute to optimize the system. Meanwhile, square titration was used to determine the optimal concentration of conjugate and MIP (He et al., 2019). The results are shown in Figure $8 \mathrm{~A}$. It could be seen that when the concentration of MIP was $1 \mathrm{mg} / \mathrm{mL}(50 \mu \mathrm{L}$ per well $)$ and the conjugate
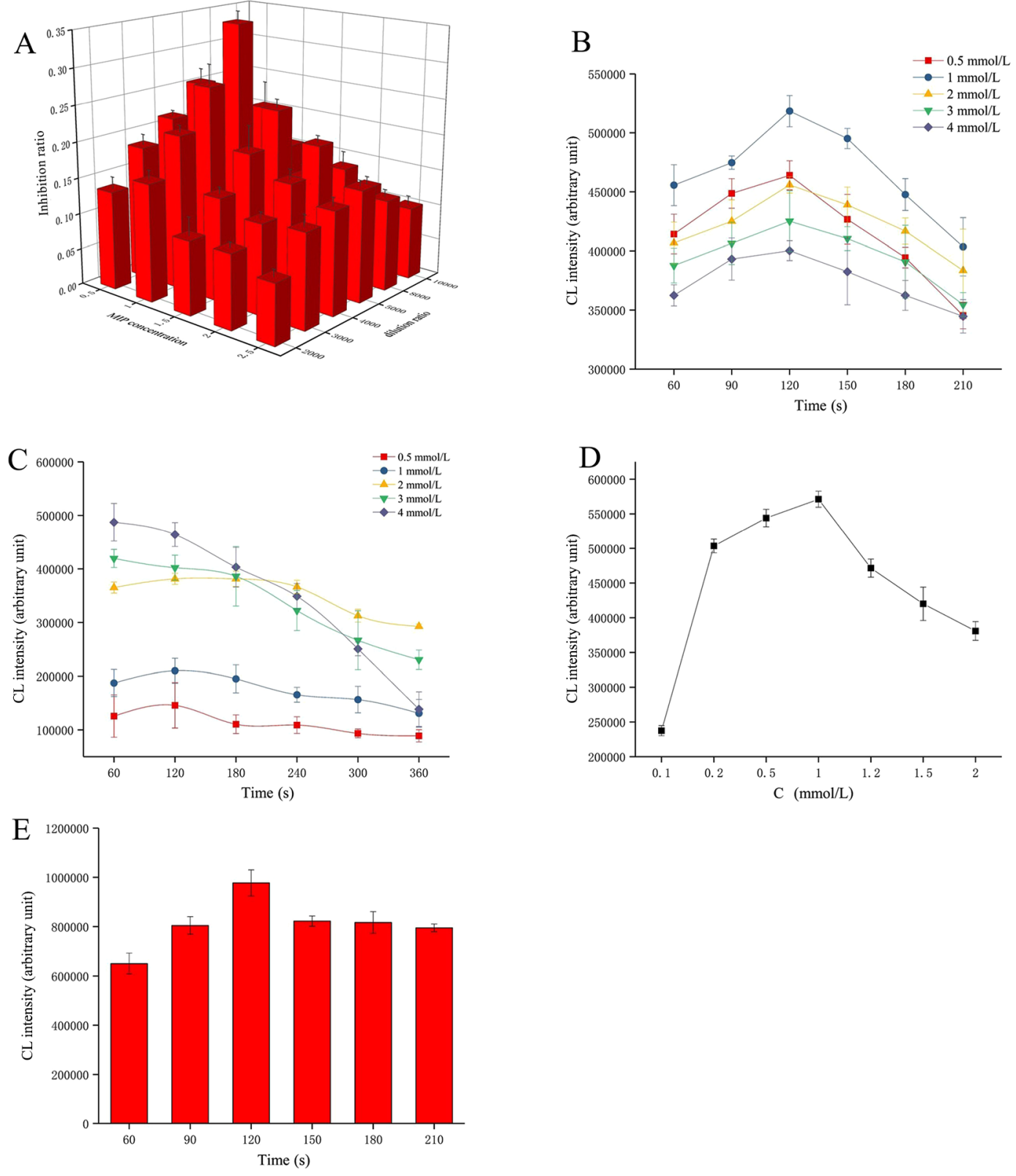

Figure 8. Condition optimization of chemiluminescence (CL) method. (A) Molecularly imprinted polymers (MIP) and conjugate; (B) concentration of luminol; (C) concentration of $\mathrm{H}_{2} \mathrm{O}_{2}$; (D) concentration of 4-(imidazol-1-yl)phenol; (E) time. Data are expressed as the mean \pm SD. 

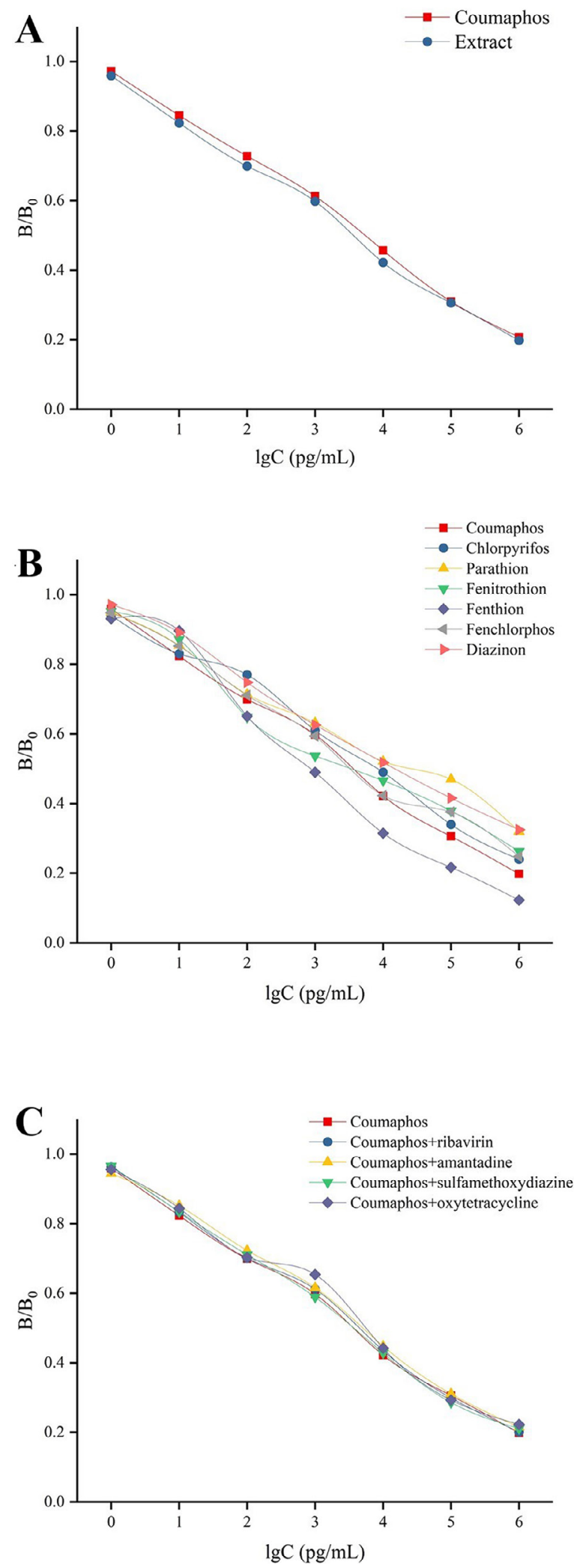

Figure 9. Results of matrix effect (A), organophosphorus (OP) inhibition curves $(\mathrm{B})$ and anti-interference study $(\mathrm{C}) . \lg \mathrm{C}=\log$ transformation of concentration; $\mathrm{B} / \mathrm{B}_{0}=$ relationship between $\mathrm{OP}$ concentration and inhibition rate. was diluted 5,000 times ( $50 \mu \mathrm{L}$ per well), the maximum inhibition rate was achieved. Therefore, these concentrations of MIP and conjugate were selected in the subsequent experiment.

CL Reagents. In this study, the luminol- $\mathrm{H}_{2} \mathrm{O}_{2}$ system was used as the luminescence system. Luminol$\mathrm{H}_{2} \mathrm{O}_{2}$ system is a common chemiluminescence system, in which the amount of luminol and $\mathrm{H}_{2} \mathrm{O}_{2}$ will affect the intensity and stability of the luminescence signal. The concentrations of luminol and $\mathrm{H}_{2} \mathrm{O}_{2}$ were optimized. Figures $8 \mathrm{~B}$ and $8 \mathrm{C}$ show that when the concentration of $\mathrm{H}_{2} \mathrm{O}_{2}$ was $2 \mathrm{mmol} / \mathrm{L}$ and luminol was $1 \mathrm{mmol} / \mathrm{L}$, the system had the maximum luminous value. After determining the concentration of $\mathrm{H}_{2} \mathrm{O}_{2}$ and luminol, we then optimized the concentration of IMP via luminescence values measured at different concentrations of IMP. The results are shown in Figure 8D. It can be seen that when the concentration of IMP was $1 \mathrm{mmol} / \mathrm{L}$, maximum luminescence value occurred.

Time. The luminous time was measured. The results are shown in Figure 8E. When adding various luminescent reagents, the maximum luminescence value was reached at $120 \mathrm{~s}$. Therefore, $120 \mathrm{~s}$ was selected as the subsequent experimental condition.

In summary, the optimal conditions of CL assay were $1 \mathrm{mg} / \mathrm{mL}$ MIP, 5,000 times the conjugate dilution, 2 $\mathrm{mmol} / \mathrm{L} \mathrm{H}_{2} \mathrm{O}_{2}, 1 \mathrm{mmol} / \mathrm{L}$ luminol, and $1 \mathrm{mmol} / \mathrm{L} \mathrm{IMP}$ dilution, and the test has a maximum luminous value of $120 \mathrm{~s}$.

Sensor Performance. Under optimized conditions, 7 OP were added to blank milk samples for evaluation. First, coumaphos was diluted with extracts from the blank milk sample, and the inhibition curves of the matrix were plotted. As shown in Figure 9A, it can be seen that the inhibition curve of the matrix-matched coumaphos was similar to that of the coumaphos standard, indicating a minimal matrix. Therefore, the extracted matrix has no effect on the representative compound, and the subsequent tests in real milk samples can be carried out (Xia et al., 2018; Zhang et al., 2018; Li et al., 2019a).

Then 7 OP were diluted with milk extract to plot the inhibition curve, and the results are shown in Figure 9B. Due to the high sensitivity of the luminescence system, all $7 \mathrm{OP}$ had low $\mathrm{LOD}$ and $\mathrm{IC}_{50}$. The $7 \mathrm{OP}$ were added to blank milk samples to assess precision and accuracy. The intraday recoveries and interday recoveries of the 7 OP were calculated in the newly prepared MIP-MCL sensors. The results are shown in Table 2 . The LOD of the $7 \mathrm{OP}$ was in the range of 1 to $3 \mathrm{pg} / \mathrm{mL}, \mathrm{IC}_{50}$ was in the range of 1 to $20 \mathrm{ng} / \mathrm{mL}$, intraday recoveries were in the range of 86.1 to $86.5 \%$, and interday recoveries were in the range of 83.6 to $94.2 \%$. During the experiment, the newly prepared MIP-MCL sensor was reused 
Table 2. Recoveries of 7 organophosphorus from the fortified blank milk samples $(n=6)^{1}$

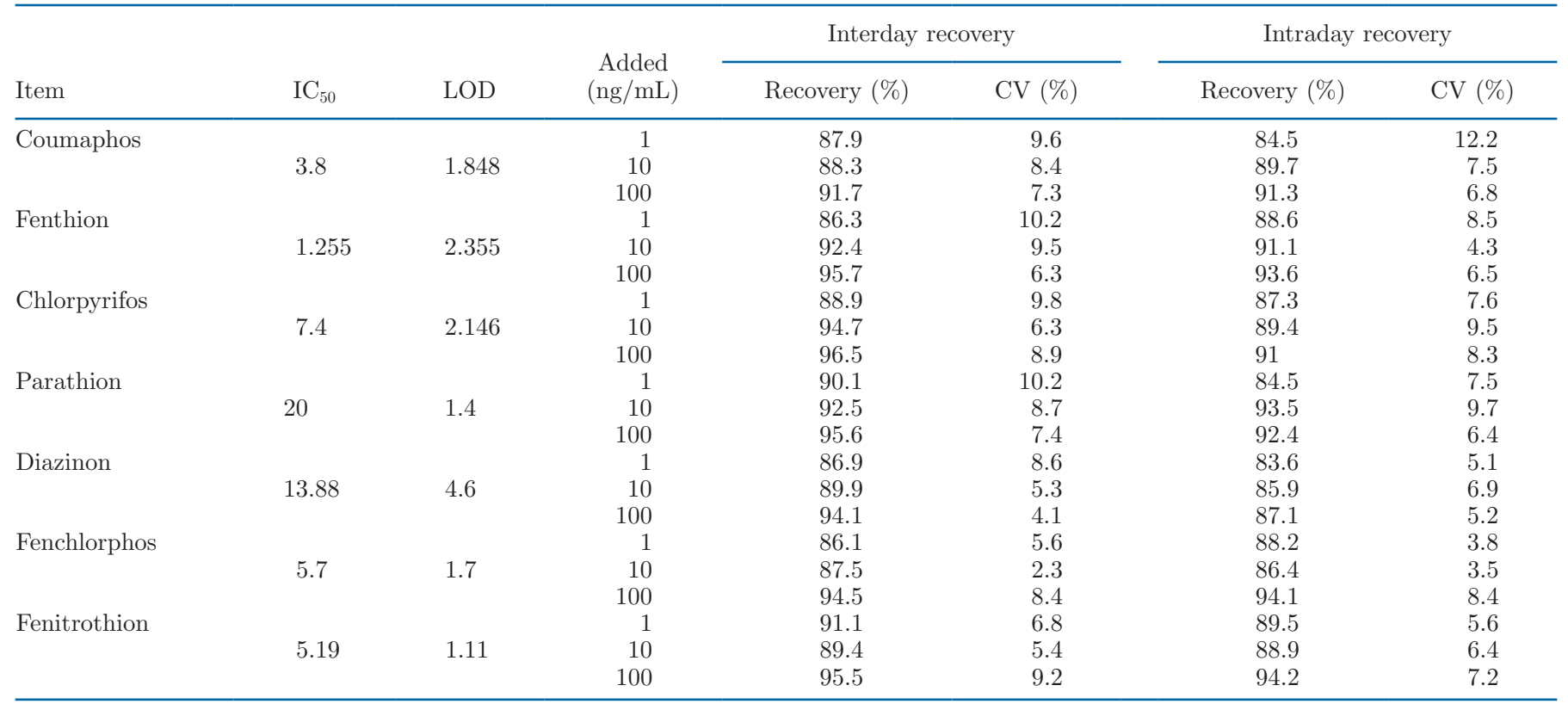

${ }^{1} \mathrm{IC}_{50}=$ half-maximal inhibition concentration, $\mathrm{ng} / \mathrm{mL} ; \mathrm{LOD}=$ limit of detection, $\mathrm{pg} / \mathrm{mL}$.

to evaluate cycling performance. The results showed that the sensor had stable $\mathrm{IC}_{50}$ (relative $\mathrm{SD}<5.5 \%$ ) when reused 5 times, When the sensor was used for the sixth time, the $\mathrm{IC}_{50}$ value started to rise sharply (relative SD > 18\%), which might be caused by the broken MIP from the inner wall. Therefore, the sensor could be reused up to 5 times.

In addition, to determine the anti-interference capability of the sensor, 4 compounds (ribavirin, amantadine, sulfamethoxydiazine, and oxytetracycline) were compared with coumaphos as the representative compound, respectively, and the inhibition curves were drawn (Figure 9C). The results showed that the $\mathrm{IC}_{50}$ and sensitivity of the sensor were almost unaffected in the presence of other compounds, indicating that the sensor was specific only to OP and could endure a high level of co-existing interferents.

Application of Sensors in Milk Samples. In this study, 60 milk samples from the local market were analyzed using MIP-MCL sensors. From the results, all the milk samples were negative.

Comparison With Related Methods. To our best knowledge, currently, there is no MIP-based CL method to detect OP. For comparison with relevant methods, the details of some previously reported ELISA-based and MIP-based assays are summarized in Table 3. Each of these related methods has one or more disadvantages: (1) only usable once, (2) few compounds tested at once, (3) not suitable for screening a large number of samples, (4) low sensitivity results in nanogram per

Table 3. Details of the previous antibody-based and molecularly imprinted polymer (MIP)-based chemiluminescence (CL) methods for organophosphorus $(\mathrm{OP})^{1}$

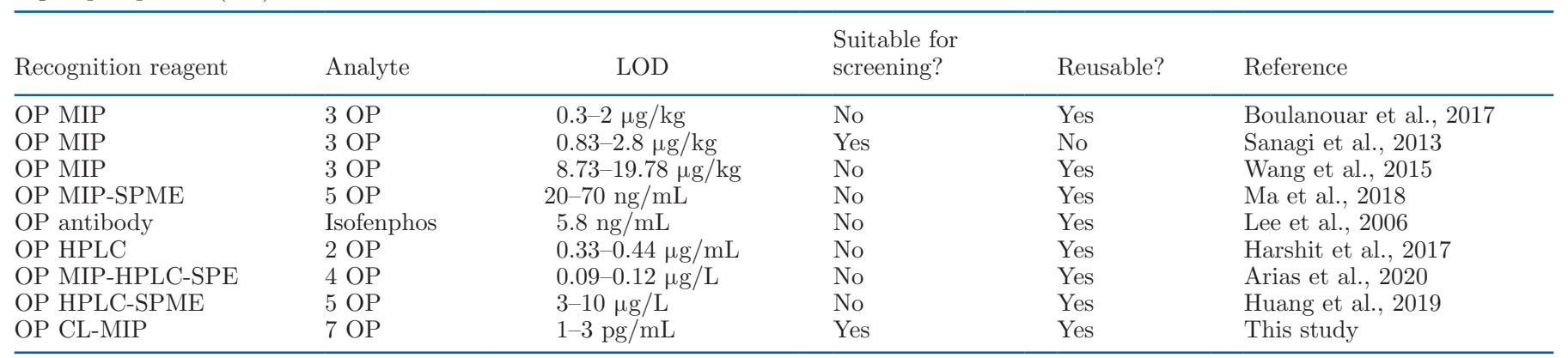

${ }^{1} \mathrm{LOD}=$ limit of detection. $\mathrm{SPME}=$ solid-phase microextraction; SPE $=$ solid-phase extraction. 
milliliter-level detection limit. Compared with previous related methods, from the view of sensitivity, detection limit, reusability, and detection ability of multiple analytes, the MIP-MCL sensor prepared in this study has better performance. In addition, the developed HPLC detection methods also have some disadvantages compared with this study. The HPLC-based methods could only detect a few $\mathrm{OP}$, and the LOD was higher than the present study (Table 3). Moreover, the operation of HPLC is tedious and takes more time, so it is not suitable for large-scale screening. Therefore, the MIPMCL method has obvious advantages compared with the HPLC method.

\section{CONCLUSIONS}

In this study, the chemical structures of 7 OP were analyzed, and synthesis of MIP was performed using coumaphos as a template molecule. The synthesized MIP was characterized by Fourier-transform infrared spectroscopy and scanning electron microscopy with good results. It was found that the 3-dimensional structure of the compound had an important effect on the specific adsorption of MIP, and the synthesized MIP can specifically adsorb 7 kinds of OP. Then, an MIP-based microtitration CL sensor was prepared to determine OP in milk samples. Results showed that the sensor achieved picogram per milliliter-level of sensitivity and high recovery, and could be reused 5 times. Taken together, the MIP-MCL sensor can therefore be used as a useful tool for OP detection in milk samples.

\section{ACKNOWLEDGMENTS}

This research was financially supported by the Precision Animal Husbandry Discipline Group Construction Project of Hebei Agricultural University (grant no.1090064; China) and the China Agriculture Research System of the Ministry of Finance and the Ministry of Agriculture and Rural Affairs (Beijing). The authors have not stated any conflicts of interest.

\section{REFERENCES}

Arias, P. G., H. Martínez-Pérez-Cejuela, A. Combès, V. Pichon, E. Pereira, J. M. Herrero-Martínez, and M. Bravo. 2020. Selective solid-phase extraction of organophosphorus pesticides and their oxon-derivatives from water samples using molecularly imprinted polymer followed by high-performance liquid chromatography with UV detection. J. Chromatogr. A 1626:461346. https://doi.org/10 .1016/j.chroma.2020.461346.

Boulanouar, S., A. Combès, S. Mezzache, and V. Pichon. 2017. Synthesis and application of molecularly imprinted polymers for the selective extraction of organophosphorus pesticides from vegetable oils. J. Chromatogr. A 1513:59-68. https://doi.org/10.1016/j .chroma.2017.07.067.
Chen, C., J. Luo, C. Li, M. Ma, W. Yu, J. Shen, and Z. Wang. 2018. Molecularly imprinted polymer as an antibody substitution in pseudo-immunoassays for chemical contaminants in food and environmental samples. J. Agric. Food Chem. 66:2561-2571. https:// doi.org/10.1021/acs.jafc.7b05577.

Chen, J., W. Zhang, Y. Shu, X. Ma, and X. Cao. 2017. Detection of organophosphorus pesticide residues in leaf lettuce and cucumber through molecularly imprinted solid-phase extraction coupled to gas chromatography. Food Anal. Methods 10:3452-3461.

Eddleston, M. 2019. Novel clinical toxicology and pharmacology of organophosphorus insecticide self-poisoning. Annu. Rev. Pharmacol. Toxicol. 59:341-360. https://doi.org/10.1146/annurev-pharmtox $-010818-021842$

Gazzotti, T., P. Sticca, E. Zironi, B. Lugoboni, A. Serraino, and G. Pagliuca. 2009. Determination of 15 organophosphorus pesticides in Italian raw milk. Bull. Environ. Contam. Toxicol. 82:251-254. https://doi.org/10.1007/s00128-008-9609-0.

Ghorbani, M., P. Mohammadi, M. Keshavarzi, M. H. Saghi, M. Mohammadi, A. Shams, and M. Aghamohammadhasan. 2021. Simultaneous determination of organophosphorus pesticides residues in vegetable, fruit juice, and milk samples with magnetic dispersive micro solid-phase extraction and chromatographic method; recruitment of simplex lattice mixture design for optimization of novel sorbent composites. Anal. Chim. Acta 1178:338802. https:// doi.org/10.1016/j.aca.2021.338802.

Harshit, D., K. Charmy, and P. Nrupesh. 2017. Organophosphorus pesticides determination by novel HPLC and spectrophotometric method. Food Chem. 230:448-453. https://doi.org/10.1016/j .foodchem.2017.03.083.

He, J., L. Song, S. Chen, Y. Li, H. Wei, D. Zhao, K. Gu, and S. Zhang. 2015. Novel restricted access materials combined to molecularly imprinted polymers for selective solid-phase extraction of organophosphorus pesticides from honey. Food Chem. 187:331-337.

He, S., L. Zhang, S. Bai, H. Yang, Z. Cui, X. Zhang, and Y. Li. 2021. Advances of molecularly imprinted polymers (MIP) and the application in drug delivery. Eur. Polym. J. 143:110179. https://doi .org/10.1016/j.eurpolymj.2020.110179.

He, T., G. N. Wang, J. X. Liu, W. L. Zhao, J. J. Huang, M. X. Xu, J. P. Wang, and J. Liu. 2019. Dummy molecularly imprinted polymer based microplate chemiluminescence sensor for one-step detection of Sudan dyes in egg. Food Chem. 288:347-353. https://doi.org/10 .1016/j.foodchem.2019.03.031.

Huang, X. C., J. K. Ma, R. X. Feng, and S. L. Wei. 2019. Simultaneous determination of five organophosphorus pesticide residues in different food samples by solid-phase microextraction fibers coupled with high-performance liquid chromatography. J. Sci. Food Agric. 99:6998-7007. https://doi.org/10.1002/jsfa.9990.

Jia, B. J., J. Huang, J. X. Liu, and J. P. Wang. 2019. Detection of chloramphenicol in chicken, pork and fish with a molecularly imprinted polymer-based microtiter chemiluminescence method. Food Addit. Contam. Part A Chem. Anal. Control Expo. Risk Assess. 36:74-83.

Kubo, T., and K. Otsuka. 2016. Recent progress in molecularly imprinted media by new preparation concepts and methodological approaches for selective separation of targeting compounds. Trends Analyt. Chem. 81:102-109. https://doi.org/10.1016/j.trac .2015.08.008.

Lee, W. Y., E. K. Lee, Y. J. Kim, W. C. Park, T. Chung, and Y. T. Lee. 2006. Monoclonal antibody-based enzyme-linked immunosorbent assays for the detection of the organophosphorus insecticide isofenphos. Anal. Chim. Acta 557:169-178. https://doi.org/10 $.1016 /$ j.aca.2005.10.007.

Li, Z. B., J. Liu, J. X. Liu, Z. H. Wang, and J. P. Wang. 2019a. Determination of sulfonamides in meat with dummy-template molecularly imprinted polymer-based chemiluminescence sensor. Anal. Bioanal. Chem. 411:3179-3189. https://doi.org/10.1007/s00216 -019-01792-4.

Li, D., S. Zhang, X. Feng, H. Yang, F. Nie, and W. Zhang. 2019b. A novel peroxidase mimetic Co-MOF enhanced luminol chemiluminescence and its application in glucose sensing. Sens. Actuators B Chem. 296:126631. https://doi.org/10.1016/j.snb.2019.126631. 
Lin, X., X. Wang, J. Wang, Y. Yuan, S. Di, Z. Wang, H. Xu, H. Zhao, C. Zhao, W. Ding, and P. Qi. 2020. Magnetic covalent organic framework as a solid-phase extraction absorbent for sensitive determination of trace organophosphorus pesticides in fatty milk. J. Chromatogr. A 1627:461387. https://doi.org/10.1016/j.chroma 2020.461387.

Ma, J. K., X. C. Huang, and S. L. Wei. 2018. Preparation and application of chlorpyrifos molecularly imprinted solid-phase microextraction probes for the residual determination of organophosphorous pesticides in fresh and dry foods. J. Sep. Sci. 41:3152-3162. https: //doi.org/10.1002/jssc.201800385.

Marques, G. L., A. A. Siqueira, V. S. Minassa, M. D. Peres, F. S. Pelicao, and K. N. Sampaio. 2018. Method validation for simultaneous determination of atropine, pralidoxime and 12 organophosphorus compounds in blood samples by means of high-performance liquid chromatography coupled with tandem mass spectrometry (LCMS/MS). J. Chromatogr. B Analyt. Technol. Biomed. Life Sci. 1097-1098:44-53. https://doi.org/10.1016/j.jchromb.2018.09.006.

Rodrigues, F. M., P. R. R. Mesquita, L. S. de Oliveira, F. S. de Oliveira, A. Menezes Filho, P. A. de P. Pereira, and J. B. de Andrade. 2011. Development of a headspace solid-phase microextraction/gas chromatography-mass spectrometry method for determination of organophosphorus pesticide residues in cow milk. Microchem. J. 98:56-61. https://doi.org/10.1016/j.microc.2010.11.002.

Sanagi, M. M., S. Salleh, W. A. W. Ibrahim, A. A. Naim, D. Hermawan, M. Miskam, I. Hussain, and H. Y. Aboul-Enein. 2013. Molecularly imprinted polymer solid-phase extraction for the analysis of organophosphorus pesticides in fruit samples. J. Food Compos. Anal. 32:155-161. https://doi.org/10.1016/j.jfca.2013.09.001.

Sun, Y., P. Gao, R. Han, C. Luo, and Q. Wei. 2021. A target-triggered signal chemiluminescence sensor for prostate specific antigen detection based on hollow porous silica encapsulated luminol by aptamers. Sens. Actuators B Chem. 333:129543. https://doi.org/10 $.1016 /$ j.snb.2021.129543.

Tiwari, M. P., and A. Prasad. 2015. Molecularly imprinted polymer based enantioselective sensing devices: A review. Anal. Chim. Acta 853:1-18. https://doi.org/10.1016/j.aca.2014.06.011.

Wang, Q., X. Zhang, Z. Xu, and H. Gao. 2015. Simultaneous determination of three trace organophosphorus pesticide residues in vegetables using molecularly imprinted solid-phase extraction coupled with high-performance liquid chromatography. Food Anal. Methods 8:2044-2051. https://doi.org/10.1007/s12161-014-0086-2.
Wei, M., X. Yan, S. Liu, and Y. Liu. 2018. Preparation and evaluation of superparamagnetic core-shell dummy molecularly imprinted polymer for recognition and extraction of organophosphorus pesticide. J. Mater. Sci. 53:4897-4912. https://doi.org/10.1007/s10853 $-017-1935-3$.

Xia, W. Q., J. Huang, G. N. Wang, J. Liu, and J. P. Wang. 2018. Molecularly imprinted polymer based microtiter chemiluminescence array for determination of phenothiazines and benzodiazepines in pork. Anal. Biochem. 554:9-15. https://doi.org/10.1016/j.ab.2018 .05 .021$.

Xin, J., X. Qiao, Y. Ma, and Z. Xu. 2012. Simultaneous separation and determination of eight organophosphorous pesticide residues in vegetables through molecularly imprinted solid-phase extraction coupled to gas chromatography. J. Sep. Sci. 35:3501-3508. https:/ /doi.org/10.1002/jssc.201200754.

Xu, Z. L., H. Wang, Y. D. Shen, M. Nichkova, H. T. Lei, R. C. Beier, W. X. Zheng, J. Y. Yang, Z. G. She, and Y. M. Sun. 2011 Conformational changes of hapten-protein conjugates resulting in improved broad-specificity and sensitivity of an ELISA for organophosphorus pesticides. Analyst 136:2512-2520. https://doi.org/10 $.1039 / \mathrm{c} 1 \mathrm{an} 15053 \mathrm{~g}$.

Zhang, T., J. Liu, and J. P. Wang. 2018. Preparation of a molecularly imprinted polymer based chemiluminescence sensor for the determination of amantadine and rimantadine in meat. Anal. Methods 10:5025-5031. https://doi.org/10.1039/C8AY01900B.

Zhao, X., W. Kong, J. Wei, and M. Yang. 2014. Gas chromatography with flame photometric detection of 31 organophosphorus pesticide residues in Alpinia oxyphylla dried fruits. Food Chem. 162:270-276. https://doi.org/10.1016/j.foodchem.2014.04.060.

\section{ORCIDS}

Yinchuan Pan (® https://orcid.org/0000-0002-9307-2577

Xu Liu $\odot$ https://orcid.org/0000-0002-0124-3739

Jing Liu @ https://orcid.org/0000-0002-8290-3320

Jianping Wang (ํ) https://orcid.org/0000-0002-2112-0218

Juxiang Liu @ i https://orcid.org/0000-0002-9065-1514

Yanxia Gao @ https://orcid.org/0000-0002-9436-693X

Ning Ma ํ https://orcid.org/0000-0001-6696-0379 